\title{
NOTAS TÉCNICAS
}

\section{Método do rolo de papel toalha modificado para a detecção de Sclerotinia sclerotiorum em sementes de feijão}

\author{
João José Dias Parisi ${ }^{1}$; Flávia Rodrigues Alves Patrício²; Silvânia Helena Furlan de Oliveira ${ }^{2}$
}

${ }^{1}$ Instituto de Botânica de São Paulo, Caixa Postal 4005, CEP 01061-970, São Paulo, SP. E-mail: joaoparisi2000@ yahoo.com.br
${ }^{2}$ Instituto Biológico, Caixa Postal 70, CEP 13001-970, Campinas, SP

Autor para correspondência: João J. D. Parisi

Data de chegada: 23/09/2004. Aceito para publicação em: 30/09/2005.

\section{ABSTRACT}

Parisi, J.J.D.; Patrício, F.R.A., Oliveira, S.H.F. Modification of the paper towel seed health test for the detection of Sclerotinia sclerotiorum in bean seeds (Phaseolus vulgaris L.), Summa Phytopathologica. v.32, n.3, p.288-290, 2006.

White mold, caused by the fungus Sclerotinia sclerotiorum (Lib.) is one of the most damaging diseases of beans. Dissemination of the pathogen by infected seeds is important because it can infest new planting areas and the disease may establish in the beginning of the crop cycle. The present work describes an adaptation of the seed health test using the germination paper towel method, originally developed for the detection of Colletotrichum lindemuthianum, for assessing the presence of S. sclerotiorum in bean seeds. The test consisted of placing bean seeds in germination paper towels, which were rolled and placed in a germination chamber and kept at $100 \%$ relative humidity and $20{ }^{\circ} \mathrm{C}$ for seven days. After this period, the infected seedlings and the dead seeds surrounded by a white cottony growth were collected and placed in a gerbox over two wet filter papers. The sclerotia characteristic of the pathogen appeared around the seeds after tree to four days of incubation. This method is relatively rapid, inexpensive, and has the additional advantage of detecting simultaneously other important plant pathogens in bean seeds, such as Colletotrichum lindemuthianum, Macrophomina phaseolina and Rhizoctonia solani.

Additional keywords: Phaseolus vulgaris L., Colletotrichum lindemuthianum, Macrophomina phaseolina, Rhizoctonia solani, white mold.

\section{RESUMO}

Parisi, J.J.D.; Patrício, F.R.A., Oliveira, S.H.F. Método do rolo de papel toalha modificado para a detecção de Sclerotinia sclerotiorum em sementes de feijão (Phaseolus vulgaris L.), Summa Phytopathologica. v.32, n.3, p.288-290, 2006.

O mofo branco do feijoeiro, causado pelo fungo Sclerotinia sclerotiorum (Lib.) de Bary, é uma das principais doenças da cultura. O patógeno pode ser disseminado por sementes infectadas, que têm um importante papel na infestação de novas áreas de plantio e no estabelecimento da doença no início do ciclo da cultura. Este trabalho apresenta uma adaptação do método do rolo de papel toalha, originalmente desenvolvido para a detecção de Colletotrichum lindemuthianum, com o objetivo de detectar a presença de S. sclerotiorum em sementes de feijão. Neste método, as sementes foram incubadas por 7 dias a $20{ }^{\circ} \mathrm{C}$ em rolos de papel toalha para germinação, sendo mantidas sob condições de $100 \%$ de umidade relativa. Após esse período, as plântulas infeccionadas e as sementes mortas, circundadas por micélio característico de $S$. sclerotiorum, foram transportadas para caixas tipo gerbox, sobre duas folhas de papel de filtro umedecido. Após 3 a 4 dias de incubação a 20 ${ }^{\circ} \mathrm{C}$ e sob regime de 12 horas de luz por 12 horas de escuro, os escleródios foram observados nas sementes e plântulas. O método foi relativamente rápido, simples e barato, além de apresentar a vantagem de possibilitar a detecção simultânea de $S$. sclerotiorum e de outros importantes patógenos transmitidos por sementes de feijão, como $C$. lindemuthianum, Macrophomina phaseolina e Rhizoctonia solani.

Palavras-chave adicionais: Phaseolus vulgaris L., Colletotrichum lindemuthianum, Macrophomina phaseolina, Rhizoctonia solani, mofo branco.

O mofo branco do feijoeiro, causado pelo fungo Sclerotinia sclerotiorum (Lib.) de Bary, é uma das principais doenças da cultura, acarretando danos severos nos plantios de inverno em áreas irrigadas $(2,6)$. A disseminação do fungo pode ocorrer pelos ascósporos, que são liberados das ascas e ejetados no ar, pelos escleródios transportados na água de irrigação e/ou associados às sementes, e por meio das sementes infectadas, que têm um importante papel na infestação de áreas indenes e no estabelecimento da doença no início do ciclo da cultura (2, 11). A infestação de novas áreas é um sério problema, pois os escleródios podem permanecer viáveis por até 8 anos no solo (11). Devido ao importante papel das sementes na disseminação da doença, Machado (5) e Menten (7) propuseram o padrão de tolerância zero para $S$. sclerotiorum em sementes de feijão e 
soja das classes básica, certificada e fiscalizada.

O fungo $S$. sclerotiorum ocorre em incidências relativamente baixas em sementes de feijão e soja, raramente ultrapassando 2 $\%$ (10), portanto os métodos para a sua detecção devem ser sensíveis, reprodutíveis e, em sistemas de produção de sementes, também é fundamental que sejam baratos e rápidos. O método do papel de filtro, com a incubação das sementes por 30 dias em temperaturas entre 5 e $7^{\circ} \mathrm{C}$ sob escuro contínuo, é o recomendado pelas Regras para Análise de Sementes (3) para verificar a presença do fungo em sementes de feijão. Entretanto, vários outros métodos também mostraram sensibilidade para a detecção de S. sclerotiorum. Menezes (6) recomenda, além da observação do lote para verificar a presença de escleródios, a incubação das sementes pelo método do papel de filtro, por um período de 10 a 15 dias, tempo necessário para a formação dos escleródios. Koch \& Menten (4) verificaram que o método do papel de filtro, com incubação por 14 dias a $15^{\circ} \mathrm{C}$ sob escuro contínuo também foi adequado para a detecção do patógeno. Peres (10) desenvolveu o meio semi-seletivo (NEON), sobre o qual as sementes são incubadas por 7 dias em temperaturas na faixa entre 14 e $20^{\circ} \mathrm{C}$ no escuro, sendo o patógeno detectado pela mudança de coloração do meio, que ocorre na presença de substâncias ácidas. O fungo S. sclerotiorum é constatado nas sementes porque produz ácido oxálico.

O método do rolo de papel toalha, originalmente desenvolvido por Anselme \& Champion (1), é recomendado para a detecção de Colletotrichum lindemuthianum $(1,3,6)$, patógeno que causa manchas facilmente observáveis nos cotilédones, mas também pode detectar aqueles que afetam sua germinação, como Macrophomina phaseolina e Rhizoctonia solani (6). Esse método, com uma modificação, tem sido empregado desde 1993 no Laboratório Central de Sementes e Mudas (LCSM) da Coordenadoria de Assistência Técnica Integral, com o objetivo principal de detectar $C$. lindemuthianum em sementes de feijão, mas também tem evidenciado a presença de S. sclerotiorum e dos demais patógenos citados anteriormente. Essa modificação permitiu a detecção de S. sclerotiorum em 17 e 18 amostras nos anos de 1993 e 1994, quando foram analisadas amostras de 437 e 618 lotes, respectivamente $(8,9)$. Todos os lotes em que o patógeno foi detectado foram provenientes de campos de produção nos quais havia ocorrido o mofo branco, indicando uma relação com o histórico do campo. Nos demais campos a doença não foi observada e também o fungo não foi constatado nas sementes.

O método do rolo de papel toalha modificado consistiu na distribuição de sementes sobre duas folhas de papel toalha para germinação, previamente umedecidas, medindo $38 \times 28 \mathrm{~cm}$. Cinqüenta sementes foram distribuídas sobre duas folhas de papel toalha sendo cobertas por outra do mesmo papel. As folhas foram dobradas no sentido da maior dimensão e enroladas em sentido perpendicular ao primeiro. Os rolos de papel foram colocados na vertical e incubados por 7 dias em câmara a $20^{\circ} \mathrm{C}$ dentro de sacos plásticos, para que mantivessem a umidade durante a incubação. Em cada amostra foram analisadas 400 sementes (5). Para a detecção de S. sclerotiorum, as plântulas com sintomas de infecção (Figura 1) e as sementes mortas, ambas circundadas por micélio cotonoso, foram retiradas dos rolos, colocadas em gerbox contendo duas folhas de papel de filtro umedecido e, em seguida, incubadas sob regime de 12 horas de luz fluorescente e 12 horas de escuro, a $20^{\circ} \mathrm{C}$, por 3 a 4 dias. Os

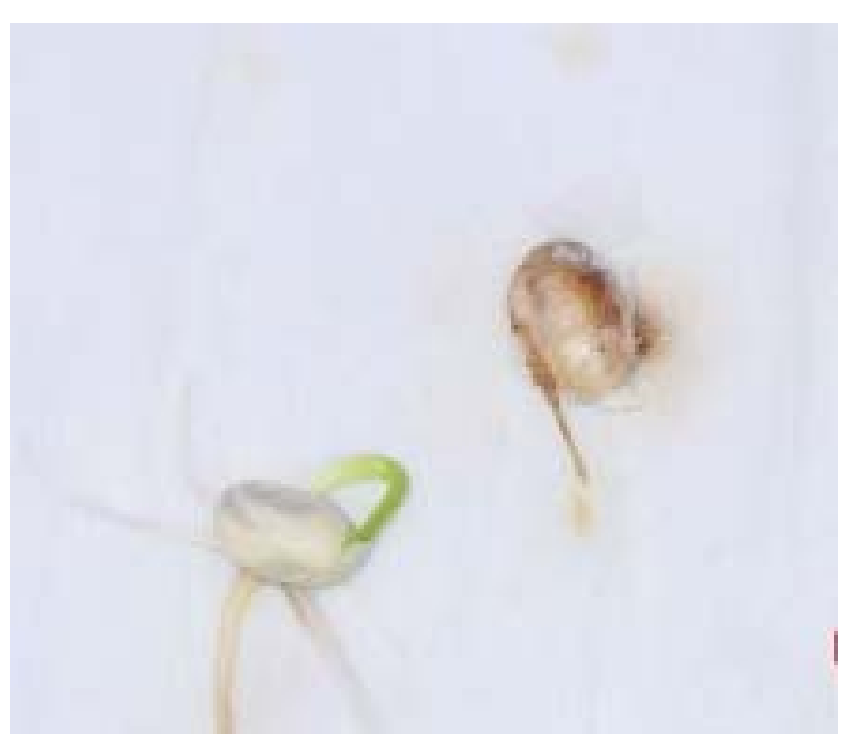

Figura 1. Plântulas de feijão sadia e com sintoma de infeção por Sclerotinia sclerotiorum no rolo de papel.

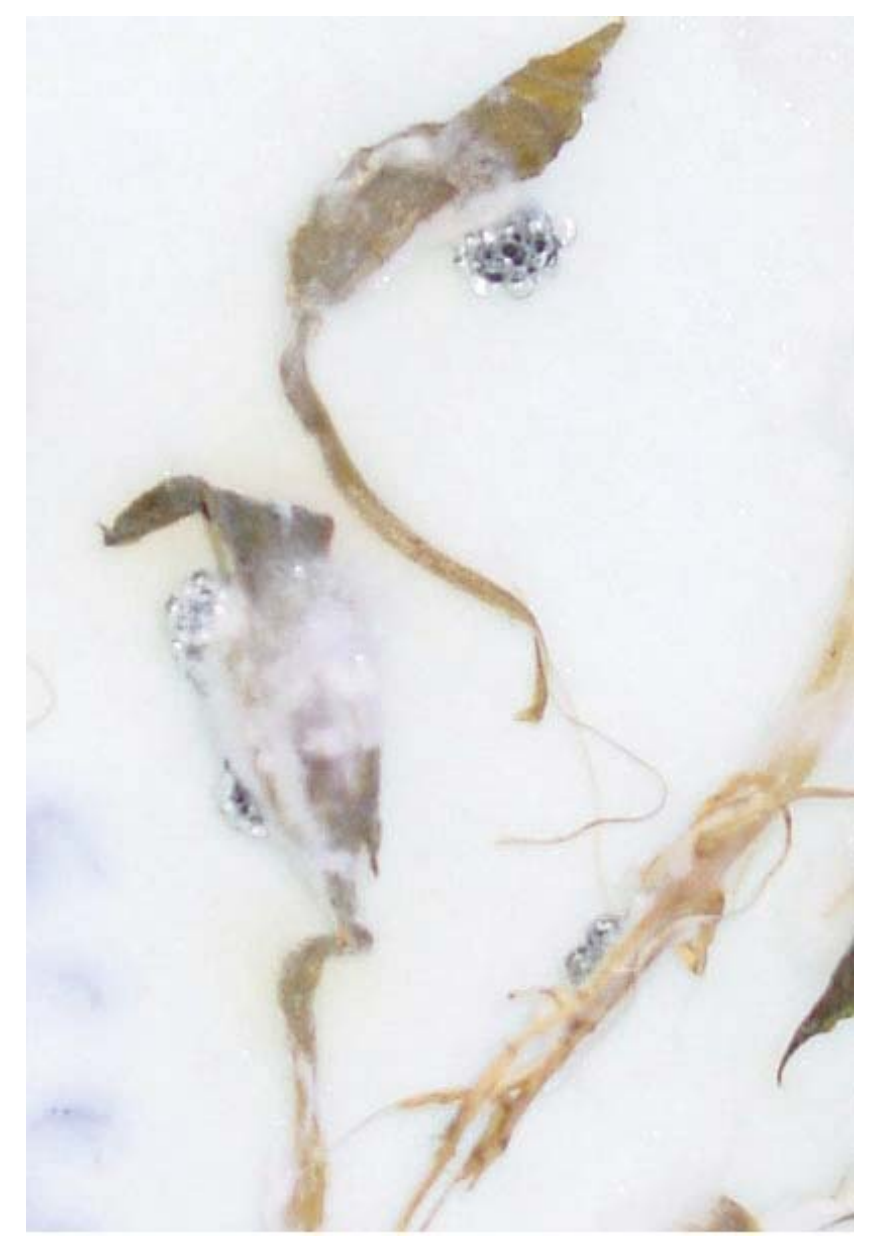

Figura 2. Plântulas de feijão após quatro dias de incubação em caixa tipo gerbox com a formação de escleródios. 
escleródios característicos de S. sclerotiorum se desenvolveram no próprio rolo, ou mais freqüentemente foram formados após a incubação, confirmando a presença do patógeno nas sementes (Figura 2).

O método do rolo modificado foi comparado ao descrito por Koch \& Menten (4), visando aferir sua sensibilidade. Uma amostra de sementes de feijão, proveniente de um campo moderadamente infestado, foi dividida em três sub-amostras. As duas primeiras foram distribuídas em rolos de papel toalha e testadas de acordo com essa nova metodologia proposta, mas os rolos foram incubados em diferentes ambientes, sendo 8 em germinador de madeira, que mantêm $100 \%$ de umidade relativa, e os outros 8 foram acondicionados em sacos plásticos e colocados em câmara, sendo periodicamente reumedecidos. A terceira sub-amostra foi incubada em placas de Petri por 14 dias em escuro contínuo (4). O fungo foi detectado em 2,24 e $2,88 \%$ das sementes mantidas no germinador e na câmara tipo B.O.D, respectivamente, e em $1,10 \%$ daquelas incubadas nas placas. A análise estatística não mostrou diferenças significativas entre os resultados, indicando que o método proposto apresenta sensibilidade semelhante à do método descrito por Koch \& Menten (4), usado para aferição.

Eventualmente o método proposto pode superestimar a incidência do fungo, caso ele se dissemine das sementes infectadas para as vizinhas. Esse fato, entretanto, tem pouca importância para S. sclerotiorum, cujo padrão de tolerância sugerido é zero. O método apresenta a vantagem de possibilitar a detecção de $S$. sclerotiorum por meio de um procedimento simples, de sensibilidade e de baixo custo, facilmente aplicável em análises de rotina, e pode também ser utilizado para a constatação simultânea de outros patógenos importantes para a cultura do feijoeiro, como, $C$. lindemuthianum, M. phaseolina e $R$. solani.

\section{REFERÊNCIAS BIBLIOGRÁFICAS}

1. Anselme, C.; Champion, R. Bean anthracnose-Phaseolus vulgaris, Colletotrichum lindemuthianum. In: ISTA Handbook in seed health testing. Z6urich:International Seed Testing Associatin (ISTA), 1981/1982. (Woking sheet № 45)

2. Bianchini, A.; Maringoni, A.C.; Carneiro, S.M.T.P.G. Doenças do feijoeiro. In: Kimati, H.; Amorim, L.; Bergamin Filho, A.; Camargo, L.E.A.; Rezende, J.A.M. Manual de fitopatologia: doenças das plantas cultivadas. São Paulo, Editora Agronômica Ceres Ltda, 1997. v.2, p.376-399.

3. Brasil. Ministério da Agricultura, Abastecimento e Reforma agrária. Regras para análise de sementes. Brasília, 1992. 365p.

4. Koch, E.F.A.; Menten, J.O.M. Método alternativo para detecção de Sclerotinia sclerotiorum em sementes de feijoeiro. Summa Phytopathologica, Jaboticabal, v.26, n.2, p.276-279, 2000.

5. Machado, J.C. Padrões de tolerância de patógenos associados às sementes. Revisão Anual de Patologia de Plantas, Passo Fundo, v.2, p.229-263, 1994.

6. Menezes, J.R. Testes de sanidade de sementes de feijão. In: Soave, J.; Wetzel, M.M.V.S. (Ed.) Patologia de sementes. Campinas: Fundação Cargill, 1987. cap. 18, p. 395-405.

7. Menten, J.O.M. Situação dos padrões de sanidade de sementes. Summa Phytopathologica, Jaboticabal, v.23, n.1, p.86-89, 1997. (Resumo).

8. Patrício, F.R.A.; Neto, M.L.; Atalla, L.M.P.; Barros, L.C.S. Qualidade sanitária de sementes certificadas de feijão produzidas pelo Estado de São Paulo na safra de 1993. Summa Phytopathogica, Jaboticabal, v.20, n.1, p.45, 1994. (Resumo).

9. Patrício, F.R.A.; Neto, M.L.; Barros, L.C.S.; Atalla, L.M.P.; Pianoski, J.; Ferreira, M.L.; Bastos, F.M. Qualidade sanitária de sementes certificadas de feijão produzidas no Estado de São Paulo em 1994. Summa Phytopathogica, Jaboticabal, v.21, n.1, p.58, 1995 (Resumo).

10. Peres, A.P. Detecção de Sclerotinia sclerotiorum (Lib.) De bary em sementes de feijão (Phaseolus vulgaris L.) e soja (Glycine $\max ($ L.) Merrill): desenvolvimento de metodologias. Lavras, 1996. 51f. Dissertação (Mestrado em Fitopatologia) - Universidade Federal de Lavras.

11. Tu, J.C. The role of white mold-infected white bean (Phaseolus vulgaris $\mathrm{L}$.) seeds in the dissemination of Sclerotinia sclerotiorum (Lib) de Bary. Journal of Phytopathology, Berlin, v.121, n.1, p.40-50, 1988. 